\title{
Strong convergence to common fixed points of a finite family of Z-operators in normed spaces
}

\author{
Isa Yildirim $^{1}{ }^{*}$, Murat Ozdemir ${ }^{2}$ \\ 1,2 Department of Mathematics, Faculty of Science, Ataturk University, Erzurum, 25240, TURKEY \\ "Corresponding Author: e-mail: isayildirim@atauni.edu.tr Tel +91-0442-2314360
}

\begin{abstract}
In this paper, we consider an implicit iteration process for approximating common fixed points of a finite family of Zoperators and we prove strong convergence theorem for such mappings in normed spaces. Also, we give a few corollaries and conclusions for same mappings. Our process contains implicit iteration processes of Xu and Ori, Zhao et.al and Rafiq. Our results generalize and improve some results in contemporary literature.
\end{abstract}

Keywords: Implicit iteration process, Common fixed point, Strong convergence.

(2000) MSC: 47H10, 47H17, 54H25

\section{Introduction and Preliminaries}

We recall some definitions in a metric space $(X, d)$. A mapping $T: X \rightarrow X$ is called an $a$-contraction if

$$
d(T x, T y) \leq \operatorname{ad}(x, y), \quad \forall x, y \in X
$$

where $a \in(0,1)$.

The map $T$ is called Kannan mapping (Kannan, 1968) if there exists $b \in\left(0, \frac{1}{2}\right)$ such that

$$
d(T x, T y) \leq b[d(x, T x)+d(y, T y)], \quad \forall x, y \in X .
$$

A similar definition is due to Chatterjea (Chatterjea 1972): there exists $c \in\left(0, \frac{1}{2}\right)$ such that

$$
d(T x, T y) \leq c[d(x, T y)+d(y, T x)], \quad \forall x, y \in X .
$$

Combining these three definitions, Zamfirescu proved the following important result (Zamfirescu, 1972).

Theorem 1.1. Let $(X, d)$ be a complete metric space and $T: X \rightarrow X$ a mapping for which there exists the real numbers $a, b$ and $c$ satisfying $0<a<1,0<b, c<1 / 2$ such that for each pair $x, y$ in $X$, at least one of the following conditions holds:

$\left(z_{1}\right) d(T x, T y) \leq a d(x, y)$;

$\left(z_{2}\right) d(T x, T y) \leq b[d(x, T x)+d(y, T y)] ;$

$\left(z_{3}\right) d(T x, T y) \leq c[d(x, T y)+d(y, T x)]$.

Then $T$ has a unique fixed point $p$ and the Picard iteration $\left\{x_{n}\right\}$ defined by

$$
x_{n+1}=T x_{n}, \quad n \in \mathrm{N}
$$


converges to $p$ for any arbitrary but fixed $x_{1} \in X$.

An operator $T$ satisfying the contractive conditions $\left(z_{1}\right)-\left(z_{3}\right)$ in the above theorem is called Zamfirescu operator (alternatively, we shall say that $T$ satisfies condition $Z$, see (Rhoades, 1974).

In 2001, Xu and Ori introduced the following implicit iteration process for a finite family of nonexpansive mappings $\left\{T_{i}: i \in \mathrm{I}\right\}$ (here $I=\{1,2, \ldots, N\}$ ), with $\left\{\alpha_{n}\right\}$ a real sequence in $(0,1)$, and an initial point $x_{0} \in K$ :

$$
\begin{gathered}
x_{1}=\alpha_{1} x_{0}+\left(1-\alpha_{1}\right) T_{1} x_{1}, \\
x_{2}=\alpha_{2} x_{1}+\left(1-\alpha_{2}\right) T_{2} x_{2}, \\
\vdots \\
x_{N}=\alpha_{N} x_{N-1}+\left(1-\alpha_{N}\right) T_{N} x_{N}, \\
x_{N+1}=\alpha_{N+1} x_{N}+\left(1-\alpha_{N+1}\right) T_{1} x_{N+1},
\end{gathered}
$$

which can be written in the following compact form:

$$
x_{n}=\alpha_{n} x_{n-1}+\left(1-\alpha_{n}\right) T_{n} x_{n} \quad \forall n \geq 1,
$$

where $T_{n}=T_{n(\bmod N)}$ (here the $\bmod N$ function takes values in $I$ ) (Xu and Ori, 2001). They proved the weak convergence of this process to a common fixed point of the finite family defined in a Hilbert space.

Later on, Chidume and Shahzad studied the strong convergence of the this implicit process to a common fixed point for a finite family of nonexpansive mappings (Chidume and Shahzad, 2005).

Zhou and Chang introduced the convergence of modified implicit iteration process for a finite family of asymptotically nonexpansive mappings in uniformly convex Banach spaces (Zhou and Chang, 2002). In 2006, Rafiq studied the following implicit iteration process for strong convergence to a common fixed point for a finite family of $Z$-operators in normed spaces,

$$
x_{n}=\alpha_{n} x_{n-1}+\left(1-\alpha_{n}\right) T_{n} x_{n}+u_{n} \quad \forall n \geq 1,
$$

where $T_{n}=T_{n(\bmod N)},\left\{\alpha_{n}\right\}$ is a sequence in $(0,1)$, and $\left\{u_{n}\right\}$ is summable sequence in $K$ (Rafiq, 2006). He proved the following results.

Theorem 1.2. Let $K$ be a nonempty closed convex subset of a normed space $E$. Let $\left\{T_{1}, T_{2}, \ldots, T_{N}\right\}: K \rightarrow K$ be $N \quad Z$ operators with $F=\bigcap_{i=1}^{N} F\left(T_{i}\right) \neq \varnothing$. From arbitrary $x_{0} \in K$, define the sequence $\left\{x_{n}\right\}$ by the implicit iteration process (5) satisfying $\sum_{n=1}^{\infty}\left(1-\alpha_{n}\right)=\infty$ and $\left\|u_{n}\right\|=0\left(1-\alpha_{n}\right)$. Then $\left\{x_{n}\right\}$ converges strongly to a common fixed point of $\left\{T_{1}, T_{2}, \ldots, T_{N}\right\}$.

Theorem 1.3. Let $K$ be a nonempty closed convex subset of a normed space $E$. Let $\left\{T_{1}, T_{2}, \ldots, T_{N}\right\}: K \rightarrow K$ be $N$ operators satisfying condition $Z$ with $F=\bigcap_{i=1}^{N} F\left(T_{i}\right) \neq \varnothing$. From arbitrary $x_{0} \in K$, define the sequence $\left\{x_{n}\right\}$ by the implicit iteration process (4) satisfying $\sum_{n=1}^{\infty}\left(1-\alpha_{n}\right)=\infty$. Then $\left\{x_{n}\right\}$ converges strongly to a common fixed point of $\left\{T_{1}, T_{2}, \ldots, T_{N}\right\}$.

Recently, Zhao et.al [13] introduced the following two implicit iteration schemes as follows:

$$
x_{n}=\alpha_{n} x_{n-1}+\beta_{n} T x_{n-1}+\gamma_{n} T x_{n}, \quad \forall n \geq 1,
$$

for fixed points of nonexpansive mapping $T$ in Banach space. And, the other iteration scheme was introduced

$$
x_{n}=\alpha_{n} x_{n-1}+\beta_{n} T_{n} x_{n-1}+\gamma_{n} T_{n} x_{n}, \quad \forall n \geq 1 .
$$

where $T_{n}=T_{n(\bmod N)}$, for common fixed points of a finite family of nonexpansive mappings $\left\{T_{i}\right\}_{i=1}^{N}$ in Banach spaces. They also proved some strong convergence theorems for such mappings.

Motivated by the above works, in this paper, we introduce the following implicit iteration process for approximating the common fixed points of $\left\{T_{1}, T_{2}, \ldots, T_{N}\right\}$.

Let $E$ be a normed space, $K$ a nonempty closed convex subset of $E$ and $\left\{T_{1}, T_{2}, \ldots, T_{N}\right\}: K \rightarrow K$ be $N \quad Z$-operators. Let $\left\{\alpha_{n}\right\},\left\{\beta_{n}\right\}$ and $\left\{\gamma_{n}\right\}$ be three real sequences in [0,1] satisfying $\alpha_{n}+\beta_{n}+\gamma_{n}=1$, we have the following iteration process: for arbitrary chosen $x_{0} \in K$,

$$
x_{n}=\alpha_{n} x_{n-1}+\beta_{n} T_{n} x_{n-1}+\gamma_{n} T_{n} x_{n}+u_{n}, \quad \forall n \geq 1
$$


where $T_{n}=T_{n(\bmod N)}$ and $\left\{u_{n}\right\}$ is summable sequence in $K$.

Remaks 1.4. (1) If $\beta_{n}=0$, then we see that (8) reduces to (5). Also, this iteration process contains the process (4) as its special case.

(2) The implicit iteration process (8) are a generalization of the implicit iteration processes (6) and (7).

The purpose of this paper is to study the strong convergence of implicit iteration process (8) to a common fixed point for a finite family of $Z$-operators in normed spaces. Our results improve and extend the corresponding results of Rafiq [6].

We need the following lemma in order to prove our main result.

Lemma 1.5. Let $\left\{r_{n}\right\},\left\{s_{n}\right\}$ and $\left\{t_{n}\right\}$ be sequences of nonnegative numbers satisfying

$$
r_{n+1} \leq\left(1-s_{n}\right) r_{n}+s_{n} t_{n} \quad \forall n \geq 1 .
$$

If $\sum_{n=1}^{\infty} S_{n}=\infty$ and $\lim _{n \rightarrow \infty} t_{n}=0$, then $\lim _{n \rightarrow \infty} r_{n}=0$ (Chang, 1997).

\section{Main results}

Theorem 2.1. Let $K$ be a nonempty closed convex subset of a normed space $E$. Let $\left\{T_{1}, T_{2}, \ldots, T_{N}\right\}: K \rightarrow K$ be $N \quad Z$ operators with $F=\bigcap_{i=1}^{N} F\left(T_{i}\right) \neq \varnothing$. From arbitrary $x_{0} \in K$, define the sequence $\left\{x_{n}\right\}$ by the implicit iteration process (8) satisfying $\sum_{n=1}^{\infty}\left(1-\alpha_{n}\right)=\infty$ and $\left\|u_{n}\right\|=0\left(1-\alpha_{n}\right)$. Then $\left\{x_{n}\right\}$ converges strongly to a common fixed point of $\left\{T_{1}, T_{2}, \ldots, T_{N}\right\}$.

Proof. Since $F=\bigcap_{i=1}^{N} F\left(T_{i}\right) \neq \varnothing$, then $Z$-operators $\left\{T_{1}, T_{2}, \ldots, T_{N}\right\}$ have a common fixed point in $K$. We suppose that $p \in F$. From each $T_{i}$ is a $Z$-operator for all $i \in \mathrm{I}$, at least one of the conditions $\left(z_{1}\right),\left(z_{2}\right)$ and $\left(z_{3}\right)$ is satisfied. If $\left(z_{2}\right)$ holds, then for $x, y \in K$

$$
\begin{gathered}
\left\|T_{i} x-T_{i} y\right\| \leq b\left[\left\|x-T_{i} x\right\|+\left\|y-T_{i} y\right\|\right] \\
\leq b\left[\left\|x-T_{i} x\right\|+\|y-x\|+\left\|x-T_{i} x\right\|+\left\|T_{i} x-T_{i} y\right\|\right]
\end{gathered}
$$

implies

From $0 \leq b<1 / 2$ we obtain

$$
(1-b)\left\|T_{i} x-T_{i} y\right\| \leq b\|x-y\|+2 b\left\|x-T_{i} x\right\|
$$

$$
\left\|T_{i} x-T_{i} y\right\| \leq \frac{b}{1-b}\|x-y\|+\frac{2 b}{1-b}\left\|x-T_{i} x\right\| .
$$

If $\left(z_{3}\right)$ holds, then similarly we obtain

Denote

$$
\left\|T_{i} x-T_{i} y\right\| \leq \frac{c}{1-c}\|x-y\|+\frac{2 c}{1-c}\left\|x-T_{i} x\right\| .
$$

$$
\delta=\max \left\{a, \frac{b}{1-b}, \frac{c}{1-c}\right\} .
$$

Then we have $0 \leq \delta<1$ and in view of $\left(z_{1}\right)$, (11)-(13) it results that the inequality

holds for all $x, y \in K$.

$$
\left\|T_{i} x-T_{i} y\right\| \leq \delta\|x-y\|+2 \delta\left\|x-T_{i} x\right\|
$$

By using (8), we have

$$
\begin{gathered}
\left\|x_{n}-p\right\|=\left\|\alpha_{n} x_{n-1}+\beta_{n} T_{n} x_{n-1}+\gamma_{n} T_{n} x_{n}+u_{n}-p\right\| \\
\leq \alpha_{n}\left\|x_{n-1}-p\right\|+\beta_{n}\left\|T_{n} x_{n-1}-p\right\|+\gamma_{n}\left\|T_{n} x_{n}-p\right\|+\left\|u_{n}\right\|
\end{gathered}
$$

Using (14) with $y=x_{n-1}$ and $x=p$, we get

$$
\left\|T_{n} X_{n-1}-p\right\| \leq \delta\left\|x_{n-1}-p\right\|,
$$


and also, for $y=x_{n}$ by using the same method, we have

Substituting (16) and (17) into (15), we obtain

$$
\left\|T_{n} x_{n}-p\right\| \leq \delta\left\|x_{n}-p\right\| .
$$

which leads to

$$
\left\|x_{n}-p\right\| \leq \alpha_{n}\left\|x_{n-1}-p\right\|+\beta_{n} \delta\left\|x_{n-1}-p\right\|+\gamma_{n} \delta\left\|x_{n}-p\right\|+\left\|u_{n}\right\|
$$

Thus, it is implies that

$$
\left(1-\gamma_{n} \delta\right)\left\|x_{n}-p\right\| \leq\left(\alpha_{n}+\beta_{n} \delta\right)\left\|x_{n-1}-p\right\|+\left\|u_{n}\right\| .
$$

$$
\left\|x_{n}-p\right\| \leq \frac{\alpha_{n}+\beta_{n} \delta}{1-\gamma_{n} \delta}\left\|x_{n-1}-p\right\|+\frac{1}{1-\gamma_{n} \delta}\left\|u_{n}\right\| .
$$

Let

and consider

$$
\begin{gathered}
A_{n}=\alpha_{n}+\beta_{n} \delta \\
B_{n}=1-\gamma_{n} \delta,
\end{gathered}
$$

$$
\begin{gathered}
\theta_{n}=1-\frac{A_{n}}{B_{n}}=1-\frac{\alpha_{n}+\beta_{n} \delta}{1-\gamma_{n} \delta}=\frac{1-\gamma_{n} \delta-\alpha_{n}-\beta_{n} \delta}{1-\gamma_{n} \delta} \\
=\frac{\left(1-\alpha_{n}\right)-\delta\left(\beta_{n}+\gamma_{n}\right)}{1-\gamma_{n} \delta}=\frac{\left(1-\alpha_{n}\right)(1-\delta)}{1-\gamma_{n} \delta} \\
\geq(1-\delta)\left(1-\alpha_{n}\right) .
\end{gathered}
$$

Since

$$
1-\delta \leq 1-\gamma_{n} \delta \leq 1,
$$

so we have

$$
\frac{A_{n}}{B_{n}} \leq 1-(1-\delta)\left(1-\alpha_{n}\right)
$$

It follows from (18) that

$$
\left\|x_{n}-p\right\| \leq\left[1-(1-\delta)\left(1-\alpha_{n}\right)\right]\left\|x_{n-1}-p\right\|+\frac{1}{1-\delta}\left\|u_{n}\right\| .
$$

From (19) and Lemma 1.5, we have

$$
\lim _{n \rightarrow \infty}\left\|x_{n}-p\right\|=0 .
$$

That is, $x_{n} \rightarrow p \in F$ and this completes the proof.

Theorem 2.1 lead to the following Corollary:

Corollary 2.2. Let $K$ be a nonempty closed convex subset of a normed space $E$. Let $\left\{T_{1}, T_{2}, \ldots, T_{N}\right\}: K \rightarrow K$ be $N$ operators satisfying condition $Z$ with $F=\bigcap_{i=1}^{N} F\left(T_{i}\right) \neq \varnothing$. From arbitrary $x_{0} \in K$, define the sequence $\left\{x_{n}\right\}$ by the implicit iteration process (7) satisfying $\sum_{n=1}^{\infty}\left(1-\alpha_{n}\right)=\infty$. Then $\left\{x_{n}\right\}$ converges strongly to a common fixed point of $\left\{T_{1}, T_{2}, \ldots, T_{N}\right\}$.

If $N=1$, implicit iteration process (7) reduces to (6). And, we obtain that the Corollary as follows:

Corollary 2.3. Let $K$ be a nonempty closed convex subset of a normed space $E$. Let $T: K \rightarrow K$ be $Z$-operator with $F=F(T) \neq \varnothing$. From arbitrary $x_{0} \in K$, define the sequence $\left\{x_{n}\right\}$ by the implicit iteration process (6) satisfying $\sum_{n=1}^{\infty}\left(1-\alpha_{n}\right)=\infty$. Then $\left\{x_{n}\right\}$ converges strongly to a fixed point of $T$.

\section{Conclusions}

The following are the conclusions that could be drawn from the study:

(1) The contractive condition (1) makes $T$ a continuous condition on $X$ while this is not the case with the contractive 
conditions (2)-(3) and (14).

(2) Our results generalize Theorem 1.2 and Theorem 1.3 of Rafiq (Rafiq, 2006).

(3) Chatterjea's and Kannan's contractive conditions (2) and (3) are both included in the class of Zamfirescu operators.

\section{Acknowledgment}

The authors would like to express their thanks to the referees for their helpful comments and suggestions.

\section{References}

Chang S.-S., 1997. On Chidume's open questions and approximate solutions of multivalued strongly accretive mapping equations in Banach spaces. Journal of Mathematical Analysis and Applications, Vol. 216, No. 1, pp. 94-111.

Chatterjea S.K., 1972. Fixed-point theorems, C.R. Acad. Bulgare Sci. Vol. 25, pp. 727-730.

Chidume C.E. and Shahzad N., 2005. Strong convergence of an implicit iteration process for a finite family of nonexpansive mappings, Nonlinear Analysis. Theory Method and Applications Vol. 62, No. 6, pp. 1149-1156.

Ciric Lj.B., 1974. A generalization of Banach's contraction principle, Proc. Am. Math. Soc. 45, 267-273.

Kannan R., 1968. Some results on fixed points, Bull. Calcutta Math. Soc. Vol. 10, pp. 71-76.

Rafiq A., 2006. Strong convergence of a modified implicit iteration process for a finite family of Z-operators, International Journal of Math.and Math.Sci., Article ID 10328, pp. 1-6.

Rhoades B.E., 1974. Fixed point iterations using infinite matrices, Trans. Amer. Math. Soc. Vol. 196, pp. 161-176.

Rhoades B.E., 1977. A comparision of various definitions of contractive mappings, Trans. Amer. Math. Soc. Vol. 226, pp. 257290.

Rus I. A., 1979. Principles and applications of the fixed point theory, (Romanian) Editura Dacia, Cluj-Napoca.

Xu H.-K. and Ori R.G., 2001. An implicit iteration process for nonexpansive mappings, Numer. Funct. Anal. and Optimiz, Vol. 22, No. 5-6, pp. 767-773.

Zamfirescu T., 1972. Fix point theorems in metric spaces, Arch. Math. (Basel), Vol. 23, pp. 292-298.

Zhou Y. and Chang S.-S., 2002. Convergence of implicit iteration process for a finite family of asymptotically nonexpansive mappings in Banach spaces, Numer. Funct. Anal. and Optimiz., Vol. 23, No. 7-8, 911-921.

Zhou J., He S. and Fu Su Y., 2008. Weak and strong convergence theorems for nonexpansive mappings in Banach spaces, Fixed Point Theo. Appl., Article ID 751383, 7 pp.

\section{Biographical notes}

Isa Yildirim received M.Sc. from Ataturk University, Turkey in 2005. He is a Junior Research Fellow (JRF) in the Department of Mathematics, Faculty of Science, Ataturk University, Erzurum, Turkey. He is pursuing his PhD under the supervision Prof. Murat Ozdemir in the field of Fixed Point Theory. His research interests include Functional Analysis (Linear and Nonlinear), Fixed Point Theory and Applications. He has published several papers in National and International Journals/Proceedings. He has participated in National and International Conferences and presented some papers. He has served as reviewer in renowned International/ National journals. Mr. Yildirim is a member of International Association of Engineers (IAENG).

Murat Ozdemir is a Professor in the Department of Mathematics, Faculty of Science, Ataturk University, Erzurum, Turkey. He has more than 20 years of experience in teaching and research. He possesses experience of guiding students of MPhil and PhD. He has published many papers in International/National journals/Proceedings. He has presented many research articles in national and international conferences. He has also carried out several research projects. His current area of research includes Real and Functional Analysis, Fixed Point Theory, Approximation Theory and Operator Theory.

Received June 2010

Accepted August 2010

Final acceptance in revised form August 2010 